\title{
Cardiac tumors: from echo to surgery
}

\section{Petra Angebrandt ${ }^{\star}$, Dejan Došen, Vojtjeh Brida, Eduard Margetić}

University of Zagreb School of Medicine, University Hospital Centre Zagreb, Zagreb, Croatia

RECEIVED:

March 11, 2017

ACCEPTED:

April 6, 2017

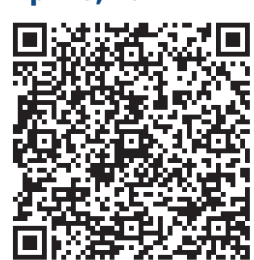

KEYWORDS: heart, tumors, echocardiography, metastasis.

CITATION: Cardiol Croat. 2017;12(4):147-148. | https://doi.org/10.15836/ccar2017.147

*ADDRESS FOR CORRESPONDENCE: Petra Angebrandt, Klinički bolnički centar Zagreb, Kišpatićeva 12, HR-10000 Zagreb, Croatia. / Phone: +385-91-159-6814 / E-mail: petraang37@yahoo.com

ORCID: Petra Angebrandt, http://orcid.org/0000-0001-5431-9736 • Dejan Došen, http://orcid.org/0000-0002-2641-4768 Vojtjeh Brida, http://orcid.org/0000-0002-8191-3615 • Eduard Margetić, http://orcid.org/0000-0001-9224-363X

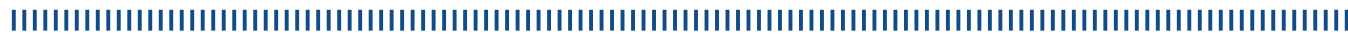

Introduction: Primary cardiac tumors are extremely rare. The incidence is less than 0.1 percent. Benign myxomas are the most common tumors and they account for $27 \%$ of primary cardiac tumors. Other benign tumors include papillary fibroelastomas, hemangiomas and mesotheliomas. Malignant primary cardiac tumors are rare. In adult, angiosarcomas, rhabdomyosarcomas, mesotheliomas and fibrosarcomas are seen. Metastatic involvement of the heart is over 20 times more common. Nonprimary cardiac tumors can include: lung and breast cancer, lymphoma, melanoma. Echocardiography is widely available and provides a simple, non-invasive technique for the initial evaluation. The major treatment is prompt surgical resection because of the risk of embolisation or other cardiovascular complications. ${ }^{1-3}$

Case report 1: MYXOMA: 62-years-old female patient with cardiac mass in left atrium, echo characteristic of myxoma with three episodes of cerebrovascular event prior to echocardiography diagnostic (Figure 1)

Case report 2: LYMPHOMA: 69-years-old male patient with primary malignant cardiac tumor: diffuse large B cell lymphoma that invaded pericardium, left and right atrium, interatrial septum and left ventricle. The diagnose was made by biopsy and afterwards chemotherapy was performed with successful results (Figure 2).

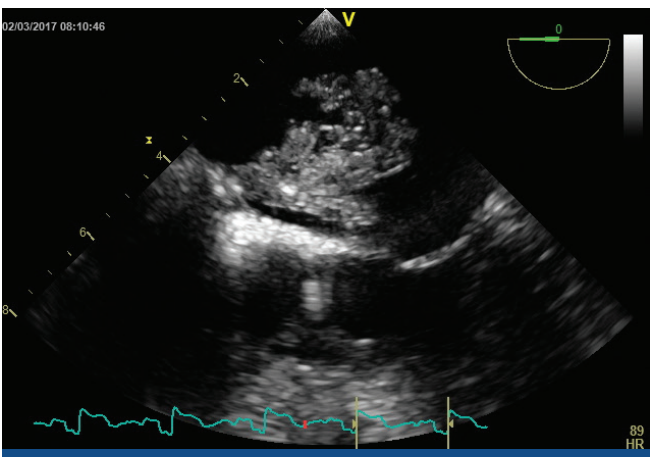

FIGURE 1. Transesofageal image of myxoma in left atrium.

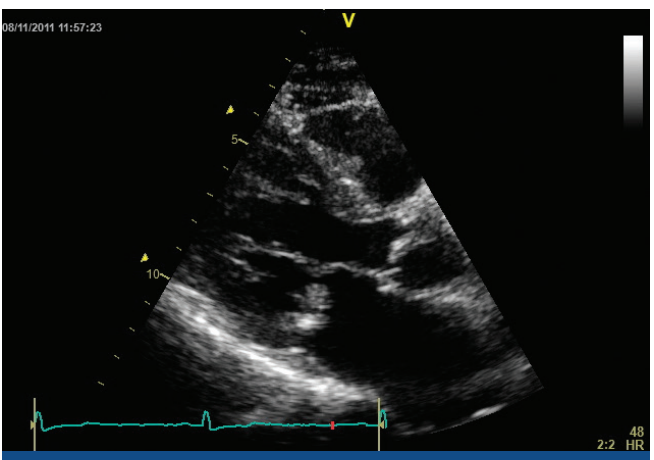

FIGURE 3. Long axis parasternal view of the solid tumor on the posterior mitral valve leaflet.

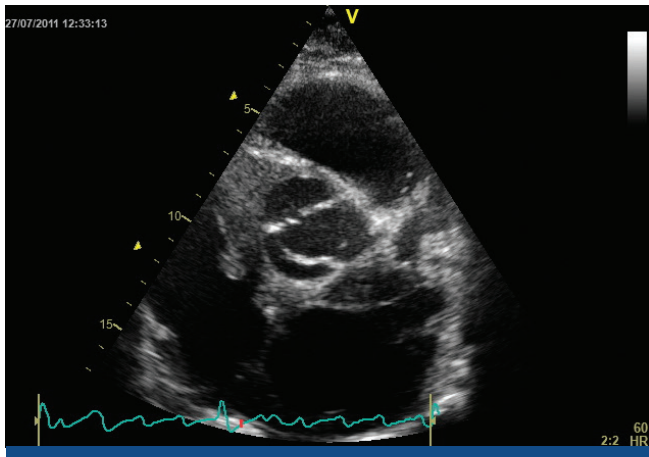

FIGURE 2. Parasternal short axis view in the aortic valve level of lymphoma of the heart: tumor is surrounding the aorta.

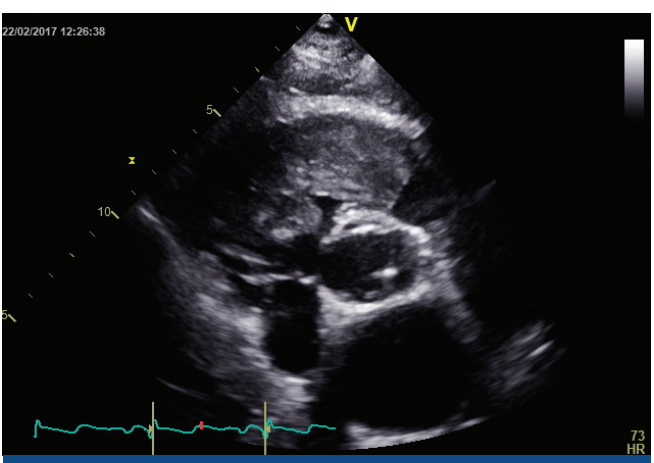

FIGURE 4. Parasternal short axis view in the aortic valve level of the rigtht ventricle mass with obstruction of the right ventricular outflow tract. 
Case report 3: HAEMANGIOMA: 53-years-old female patient with cardiac mass on posterior mitral valve leaflet with wide base on cusps. The mass was vascularized with small branch of the left circumflex artery which was seen during coronarography procedure. Patohistology showed that the mass was haemangioma of the heart (Figure 3).

Case report 4: RIGHT VENTRICLE CARDIAC MASS WITH RVOT OPSTRUCTION: 66-years-old male patient with cardiac mass in right ventricle $(3 \times 6 \times 8.5 \mathrm{~cm}$ in dimension) with RVOT obstruction and with secondary $5 \mathrm{~cm}$ big lesion in the liver highly suspected for hepatocellular carcinoma. MRI showed no signs of primary cardiac tumor, rather tumor metastasis (Figure 4).

Conclusion: Sometimes pathologically benign cardiac tumors can have "malignant" hemodynamic consequences if it obstructs the normal pattern of the blood flow. Thus, the echocardiography examination includes definition of both the anatomic extent of a cardiac tumor and its physiologic consequences. Even though, cardiac tumors are rare, sometimes we can find the most „strange"echocardiography and clinical manifestation.

LITERATURE IIIIIIIIIIIIIIIIIIIIIIIIIIIIIIIIIIIIIIIIIIIIIIIIIIIIIIIIIIIIIIIIIIIIIIIIIIIIIIIIIIIIIIIIIIIIIIIIIIIIIIIIIIIIIIIIIIIIIIIIIIIIIIIIIIIIIIIII

1. Reynen K. Frequency of primary tumors of the heart. Am J Cardiol. 1996 Jan 1;77(1):107. https://doi.org/10.1016/S0002-9149(97)89149-7

2. Lam KY, Dickens P, Chan AC. Tumors of the heart. A 20-year experience with a review of 12,485 consecutive autopsies. Arch Pathol Lab Med. 1993 0ct;117(10):1027-31. https://www.ncbi.nlm.nih.gov/pubmed/8215825

3. Salcedo EE, Cohen GI, White RD, Davison MB. Cardiac tumors: diagnosis and management. Curr Probl Cardiol. 1992 Feb;17(2):73-137. https://doi.org/10.1016/0146-2806(92)90025-J 